\title{
As linhas poéticas da educação e da pesquisa em Jorgge Menna Barreto e Ricardo Basbaum
}

\author{
Vagner Godói \\ Universidade Estadual Paulista - Franca
}

\begin{abstract}
Resumo
Ricardo Basbaum e Jorgge Menna Barreto são artistas, pesquisadores e professores universitários, têm um corpo teórico consistente de textos, incluindo dissertação e tese, se engajam em publicações, oficinas e palestras. Eles ilustram a conexão entre a universidade e os mais variados circuitos da arte através da educação e da pesquisa, até o momento em que essas questões não são apenas condições institucionais, mas são, antes, qualidades constitutivas de seus projetos poéticos. Assim, o propósito deste estudo, a partir de uma perspectiva historiográfica da arte, é delimitar a importância para a arte contemporânea das linhas poéticas tanto da educação quanto da pesquisa, ambas parte de um fenômeno maior de interesse da arte sobre o conhecimento.
\end{abstract}

Palavras-chave: Artes Visuais. Arte Contemporânea. Pesquisa Artística. Virada Educacional. Discursividade.

\section{Projeto Matéria}

Em 2004, Jorgge Menna Barreto, atualmente professor da Universidade da Califórnia Santa Cruz (UCSC), foi selecionado para participar do Programa de Exposições do Centro Cultural São Paulo (CCSP), o que coincide com a entrada do artista no mestrado de "Poéticas Visuais" na Escola de Comunicações e Artes da Universidade de São Paulo (ECA-USP), escola pioneira no desenvolvimento da pesquisa de artista na universidade. Para o CCSP o artista criou a obra de pesquisa Projeto Matéria, que pode ser definida, de forma geral, como uma oficina sobre arte contemporânea, cujo tema é o site-specific, realizada no espaço reservado ao artista, agora "transformado em uma 'sala de aula"' (BARRETO, 2007, p. 122). Uma chamada pública foi aberta para a seleção dos alunos, o que resultou em um grupo de, mais ou menos, 18 pessoas. A oficina constitui-se em oito aulas ministradas em colaboração com convidados, um grupo significativo de artistas e pesquisadores emergentes da arte brasileira naquele momento, pessoas que continuarão em outros contextos e situações na trajetória de Jorgge Menna Barreto. $\mathrm{O}$ artista diz que seu papel nas aulas foi o de facilitador ou mediador, já que essas eram conduzidas pelos convidados, chamados a colaborar sobre o tema colocado e a partir dos interesses do artista sobre a trajetória de pesquisa artística ou acadêmica desses convidados à época. 


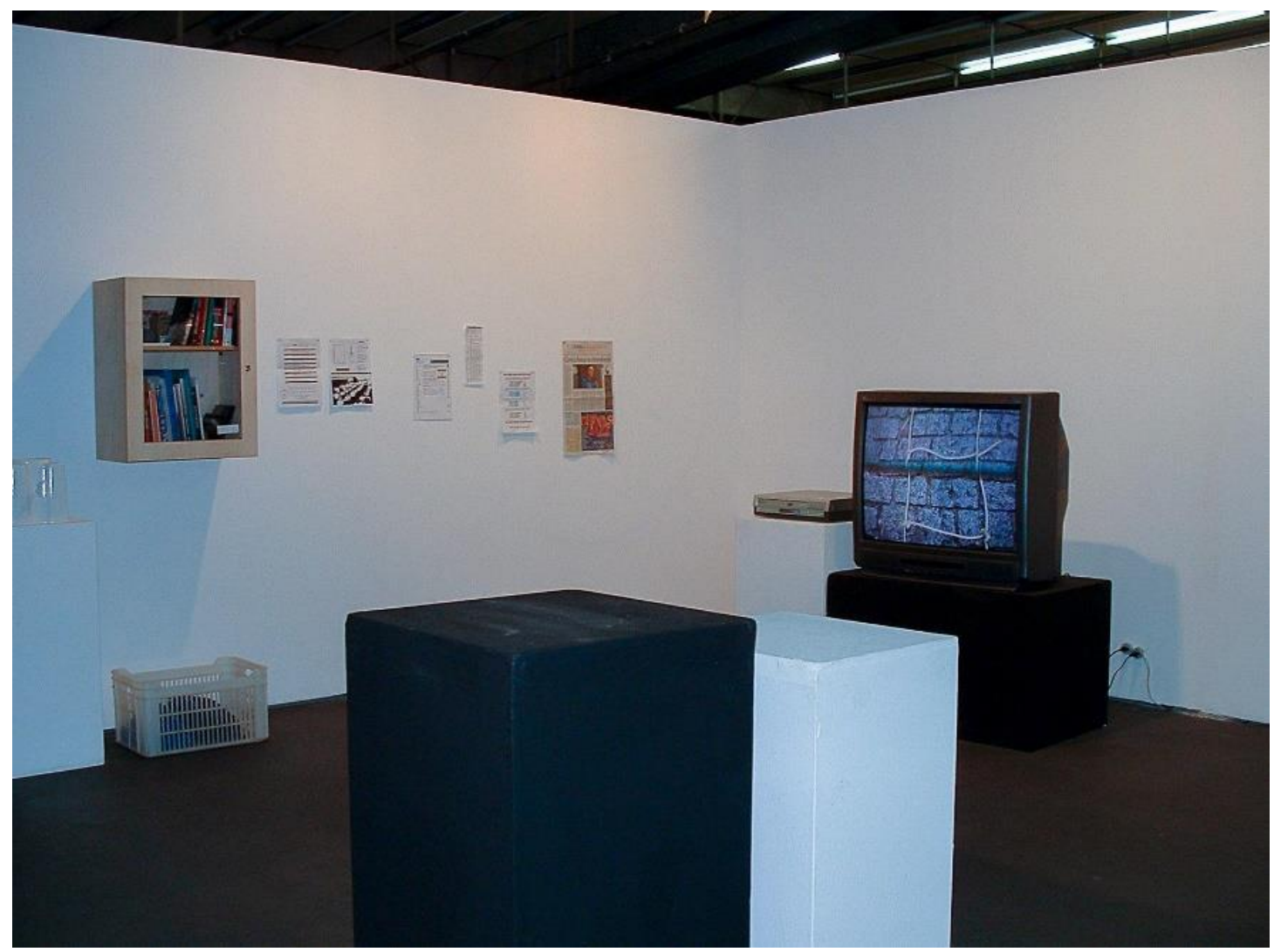

Figura 1 - Jorgge Menna Barreto, Projeto Matéria, 2004, Centro Cultural São Paulo (fotografia: cortesia do artista)

Entre os dispositivos, estruturas, ferramentas e objetos utilizados por Jorgge Menna Barreto em Projeto Matéria, próprios a uma oficina, estão as mesas e cadeiras emprestadas da biblioteca do CCSP, impressões em A4, folhas para rascunho, lápis e canetas, quadronegro, projetor de vídeo, bebedouro, engradados plásticos para guardar objetos. Um pequeno armário abrigava cerca de 30 livros relacionados ao tema da oficina, entre eles One Place After Another, de Miwon Kwon; um livro organizado por Jacques Revel sobre micro-história, chamado Jogos de escala; um livro sobre microssociologia de Erving Goffman; Além dos mapas, de Cristina Freire; Distúrbio eletrônico, do Critical Art Ensemble; livros sobre Richard Serra e Cildo Meireles; o catálogo da exposição Claraluz, de Regina Silveira, que ocupou o Centro Cultural Banco do Brasil de São Paulo (CCBB SP) em 2003; o catálogo do Panorama da Arte Brasileira de 2001; a coletânea de textos sobre Arte contemporânea brasileira, organizado por Ricardo Basbaum; um dicionário inglês-português/português-inglês para uma eventual tradução. Quem se deparava com o espaço fora dos horários da oficina, que ficava aberto ao público como as outras exposições da coletiva, tinha acesso à "sala de aula", aos folhetos de divulgação e ao vídeo de uma oficina-intervenção similar chamada "Adesão, Embate e Indiferença", que havia ocorrido em dezembro de 2003 no Espaço de Arte 
Contemporânea $803 e 804^{1}$, um ensaio para o que depois foi desenvolvido em Projeto Matéria. Uma das paredes que delimitavam o espaço foi pintada com tinta lousa, como se fosse em uma sala de aula ou como nos quadros-negros de Joseph Beuys. A parede não era apagada depois dos encontros e exibia os vestígios do que havia se passado na aula como textos, inscrições, diagramas, palavras-chave. Planos de ensino expostos em uma parede também podem ser considerados parte dos dispositivos, estruturas e objetos utilizados por Jorgge Menna Barreto nessa obra de pesquisa. Antes das exposições principais dedicadas aos artistas, que aconteciam durante $o$ ano, o programa do CCSP fez uma primeira grande mostra coletiva com todos os selecionados, como uma espécie de apresentação. Sobre a ideia do que expor nessa coletiva, o artista diz que aproveitou o momento para divulgar o curso. 0 artista deixou disponível um folheto sobre como se inscrever para a oficina, bem como uma coleção de planos de ensino de artistas brasileiros que atuam como professores ${ }^{2}$. Esses planos, afixados em uma parede, podiam ser retirados e levados para uma mesa para consulta. Jorgge Menna Barreto (2007, p. 122) diz que nessa mostra interessou-lhe, "a partir dessa coleção, fazer um mapeamento possível da atuação do artista como professor".

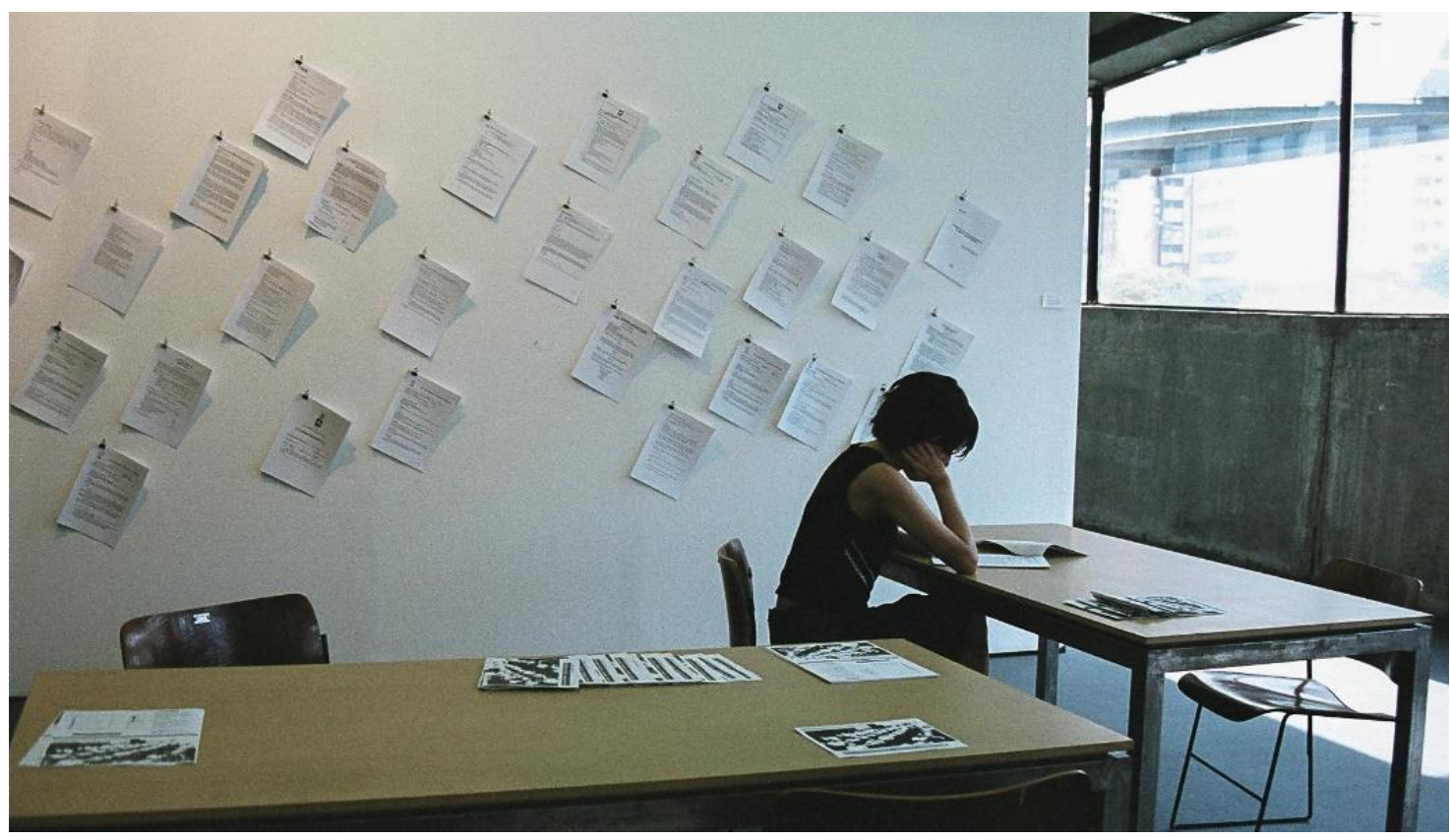

Fig. 2 - Jorgge Menna Barreto, Projeto Matéria, 2004, Centro Cultural São Paulo (fotografia: cortesia do artista)

\footnotetext{
${ }^{1}$ O espaço 803 e804 funcionou entre 2003 e 2004 em uma sala comercial de um edifício no centro de Florianópolis, mantido pelos artistas Regina Melim, Raquel Stolf, Edmilson Vasconcelos e Yiftah Peled. 2 Planos de ensino reunidos na época de disciplinas como "Laboratório de criação de textos I", de Elida Tessler (UFRGS); "O espectro matérico desierarquizado como suporte da obra", de Raquel Stolf (Udesc), "A filosofia da fotografia de Vilém Flusser", de Mario Ramiro (USP), "Processos, mediações e ampliações do corpo na arte contemporânea", de Regina Melim (Udesc). Os arquivos desses planos foram disponibilizados por Jorgge Menna Barreto.
} 
O estilo das aulas variava de professor para professor. A aula da artista Carla Zaccagnini, "O texto crítico e o texto como obra", falou sobre as questões levantadas para a dissertação de mestrado da artista ${ }^{3}$, defendida naquele ano. "A desmaterialização do objeto artístico: Conceitualismo" foi o tema da aula apresentada por Cristina Freire, sobre a arte de processo dos anos 1970 que pertence ao acervo do Museu de Arte Contemporânea da Universidade de São Paulo (MAC-USP), objeto principal de estudo dessa pesquisadora. A aula "A escuta do site: táticas de mapeamento do lugar" foi dada por Tatiana Ferraz, artista e professora no Instituto de Artes da Universidade Federal de Uberlândia (UFU). A artista Raquel Garbelotti, artista e professora da Universidade Federal do Espírito Santo (UFES), falou em sua aula sobre "O cultivo do site: formas de pertencimento". Regina Melim, artista e professora da Universidade do Estado de Santa Catarina (Udesc), discorreu sobre "A sala de aula: espaço de performação", entendendo a sala de aula também como um lugar de performance artística, onde professor e alunos participam. No dia da artista Graziela Kunsch discutiu-se a relação entre "Registro, documentação e responsabilidade". Uma das aulas programadas, a da artista Ana Maria Tavares, da ECA-USP, que teria por tema o "site-specific deslocado", ideia defendida em sua tese de doutorado, não ocorreu por incompatibilidade de agenda. Os encontros, que no plano original ocorreriam em dois momentos na semana, acabaram acontecendo em apenas um, o que fez o projeto exceder o período estipulado de quatro semanas da mostra no CCSP. Esse fato, aliado a problemas de agenda dos convidados, deslocou o restante dos encontros para a EXO ${ }^{4}$ e a Casa da Grazi ${ }^{5}$, espaços independentes e familiares ao artista naquela época.

\footnotetext{
${ }^{3}$ Ver: Zaccagnini, 2004.

${ }^{4}$ EXO experimental.org foi uma plataforma de pesquisa desenvolvida por Ligia Nobre e Cécile Zoonens entre 2002 e 2007 em São Paulo.

${ }^{5}$ Espaço independente de exposições e residências artísticas mantido na própria residência da artista Graziela Kunsch em São Paulo.
} 


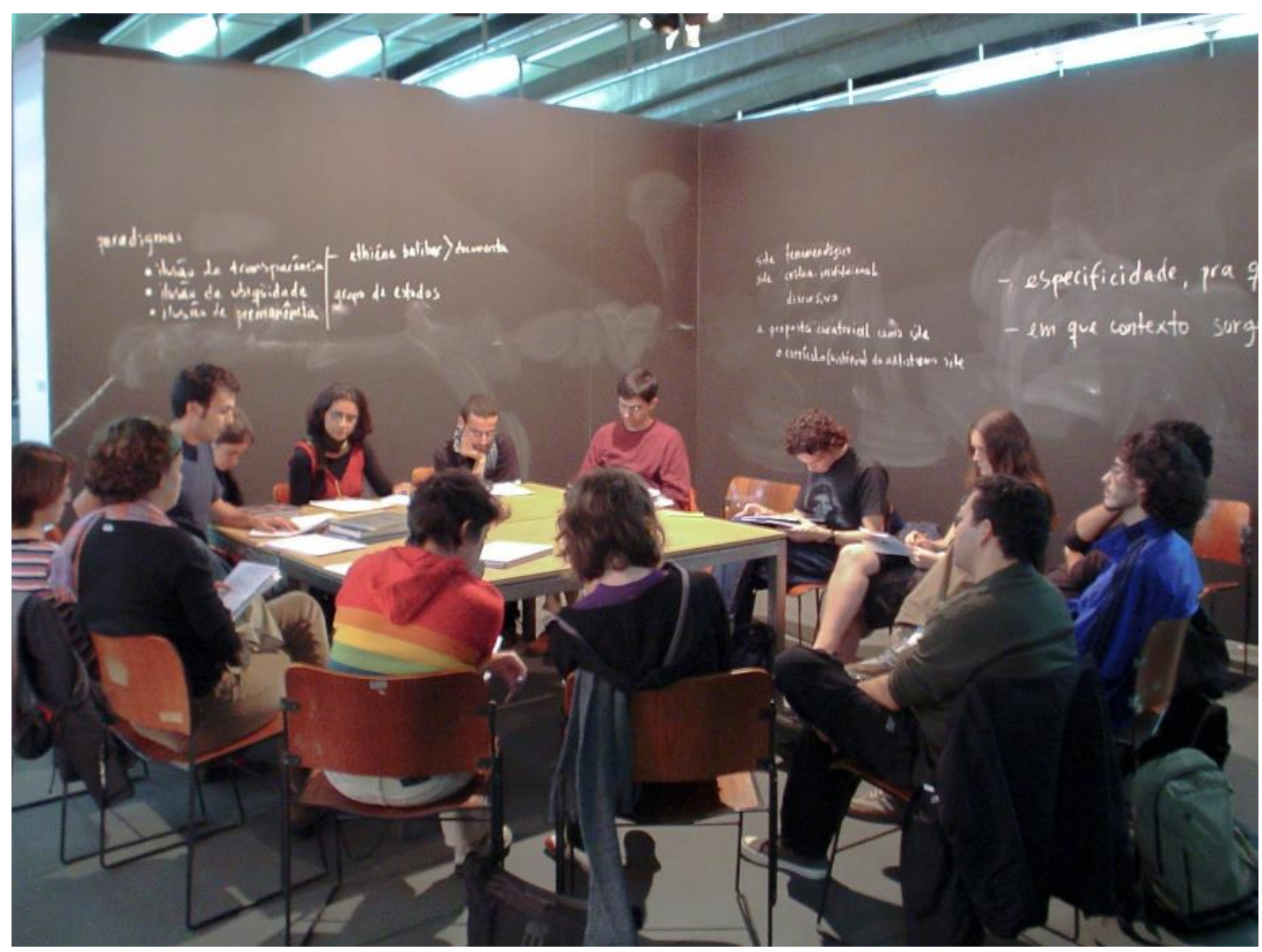

Fig. 3 - Jorgge Menna Barreto, Projeto Matéria, 2004, Centro Cultural São Paulo (fotografia: cortesia do artista)

A aula de Ricardo Basbaum, artista e professor do Instituto de Arte e Comunicação Social da Universidade Federal Fluminense (IACS UFF), consistiu em uma dinâmica de grupo que é parte de sua série eu-você: coreografias, jogos e exercícios. A série é composta de dinâmicas em que dois grupos, vestindo camisetas estampadas com os pronomes "eu" ou "você", dançam ou jogam a partir de instruções e improvisações. Essas dinâmicas são filmadas e podem ser exibidas. Jorgge Menna Barreto (2007, p. 126) conta que convidou Ricardo Basbaum porque ele já vinha considerando há algum tempo seus cursos e oficinas enquanto "extensões do seu exercício como artista, e não como uma atividade paralela", e também porque Projeto Matéria procurava seguir o mesmo caminho, de "investigar cruzamentos possíveis entre o campo da arte e o do ensino da arte".

\section{Linha poética da educação}

Muitos artistas trataram de educação em suas obras, até o limite em que processos ou dispositivos educativos, como aulas, dinâmicas, palestras, bibliotecas e grupos de estudo, tomam parte na obra ou passam a ser a própria obra de arte. Os artistas inspiram-se no sistema de ensino, no ambiente intelectual proporcionado pelos estudos, ou apropriam-se das ações educativas e de mediação realizadas em exposições. Entre os exemplos históricos, podem ser citados: Robert Morris e sua palestra-performance 21.3, realizada em 1964, 
paródia em que o artista dubla uma conferência do historiador da arte Erwin Panofsky; Allan Kaprow, que participou em 1966, junto do educador Herbert Kohl, de um experimento educacional chamado Project Other Ways de educação artística para alunos da escola pública da cidade de Berkeley (CA). Kaprow também é conhecido por suas Activities, ações e experiências cotidianas como dinâmicas, realizadas a partir de roteiros feitos com a participação de seus alunos do California Institute of Arts (CalArts), e também por suas reflexões sobre a educação e a participação do público presentes nas partes 1 (1971), 2 (1972) e 3 (1974) do texto "The Education of the Un-Artist";; Robert Filliou, que além de lançar o livro Teaching and Learning as Performing Arts ${ }^{7}$, manteve com o artista Georg Brecht o projeto-loja La cedille qui sourit em Villefranche-sur-Mer, cidade litorânea francesa próxima a Cannes, lugar em que foi desenvolvido em 1966 a Non-École de Villefranche, uma ideia de escola de arte livre; Lygia Clark, que deu aulas na Faculdade de Artes Plásticas St. Charles da Sorbonne, entre 1970 e 1976, período em que criou importantes proposições e experiências em suas aulas, que ficavam no limite com a terapia, de forma colaborativa com seus alunos, como Baba antropofágica e Túnel, em 1973; Rede de elásticos e Flor: relaxação, em 1974, Cabeça em 1975, que culminaram, a partir de 1978, nas sessões de Estruturação do Self; Tim Rollins desenvolveu a partir de 1981 o projeto Art and Knowledge Workshop, oficinas de arte realizadas em um centro comunitário com um grupo de crianças em situação de risco social do South Bronx em Nova York, grupo que foi chamado de KOS (Kids of Survival); Andrea Fraser, com a performance de crítica institucional chamada Museum Highlights: A Gallery Talk, de 1989, em que a artista se passava por uma monitora voluntária do museu, personagem fictício chamado Jane Castleton.

Joseph Beuys foi um dos primeiros a pensar as características artísticas e performáticas da aula, da palestra, do debate e também da instituição de ensino, transformando a educação em uma das linhas poéticas da obra de arte. Essas ações de caráter pedagógico desdobram sua ideia de Escultura Social/ Arquitetura Social ${ }^{8}$, no qual é articulada a crença na capacidade da arte de transformar as instituições, como a escola e universidade, e de os indivíduos moldarem a sociedade através da participação em cocriação com os artistas, produzindo juntos significados e conhecimentos através de engajamento, nos limites entre arte e vida. São suas as declarações "todo mundo é artista" e "ser professor é minha maior obra de arte". A partir dos anos 1970, Beuys criou performances ${ }^{9}$ em que discursava e discutia temas como política e arte, tópicos como democracia, socialismo e liberdade, para uma classe ou plateia. Essas performances foram documentadas em uma série de fotografias e resultaram em

\footnotetext{
${ }^{6}$ Ver: Kaprow, 1993.

7 Ver: Filliou, 1970.

8 Ver: Beuys, 1993.

${ }^{9}$ Ver a conferência realizada por Beuys em Roma em 1971, traduzida para o português em: Beuys, 2009.
} 
lousas com inscrições, anotações, palavras-chave e diagramas, que não foram apagadas depois de utilizadas nas falas do artista. Beuys teve bastante reconhecimento em duas documentas de Kassel, colocando a pedagogia como um dos meios e materiais (políticos) do artista. Em Escritório para a democracia direta através de referendo, Beuys permaneceu disponível no espaço reservado a ele no Fridericianum, no horário de funcionamento da documenta 5, de 1972, durante os 100 dias de sua duração, para discutir reforma eleitoral com o público, além de temas como a relação arte e política, capitalismo, educação, religião etc. Em 1973, com Heinrich Böll, estabeleceu a Universidade Internacional Livre para a Criatividade e a Pesquisa Interdisciplinar (FIU) ${ }^{10}$, em seu estúdio em Düsseldorf, como um local de estudo aberto e livre de expressão criativa e democrática, após ser despedido da Academia de Artes de Düsseldorf, por discordar dos parâmetros de ingresso dos alunos e por usar métodos experimentais de ensino. Em 1977, ele levou a FIU para a documenta 6, onde realizou os 100 dias de Universidade Internacional Livre, que foi constituído de seminários, oficinas e projeções de filmes, no espaço reservado a ele, contando com a colaboração de palestrantes convidados de diversas áreas, como da política, da economia, música, pedagogia etc.

Claire Bishop (2012, p. 241-274) coloca Beuys como uma das referências históricas mais conhecidas para os artistas contemporâneos, de exemplo de engajamento com pedagogias alternativas e experimentais, ao lado de Luis Camnitzer, Lygia Clark, Jef Geys e Tim Rollins. No último capítulo do livro Artificial Hells, dedicado a projetos pedagógicos e a sala de aula como obra de arte, Bishop analisa as obras educativas de alguns artistas da nova geração ${ }^{11}$ - como Tania Bruguera, com Cátedra Arte de Conducta, realizada entre 2002 e 2009; Paul Chan, com Waiting for Godot in New Orleans, de 2007; Paweł Althamer, com Einstein Class, de 2005; e Thomas Hirschhorn, exemplificado com 24h Foucault -, e mostra como esses trabalhos se colocam novos e diferentes de outras práticas relacionais, ao trazerem uma abordagem pedagógica aos trabalhos.

Embora os artistas contemporâneos compartilhem o interesse pela aula participativa como obra de arte e pelas relações do artista-professor com o aluno-participador, há uma grande diferença em relação ao tom e à construção da imagem do artista. O estilo de Beuys de dar aula, ainda que promovendo temas não autoritários e não hierárquicos, em uma

\footnotetext{
${ }^{10}$ Ver: Beuys e Böll, 1974.

11 Também é importante que sejam citados aqui outros expoentes internacionais da arte que ficam no limite com a educação, como: Copenhagen Free University, que existiu entre 2001 e 2007 como um espaço independente de ensino e pesquisa mantido pelos artistas Henriette Heise e Jakob Jakobsen; Escuela Panamericana del Desasosiego, de Pablo Helguera, que em 2006 percorreu o continente americano com uma "escola portátil", em várias paradas do Alaska até a Terra do Fogo, com mostras de vídeos, mesas redondas e palestras, realizadas em colaboração com organizadores locais; e Paraeducation Department, organizado pela artista Sarah Pierce em 2004, com a curadora Annie Fletcher, que constituiu espaço informal de autoaprendizado, dentro da exposição Tracer, colaboração entre os espaços de arte contemporânea TENT e Witte de With de Roterdã.
} 
tentativa de discurso democrático, se mantinha sob uma autoridade e aura mítica, em vista de sua condição de professor utópico e artista-gênio, inerente à sua própria obra e imagem. Os artistas, nos últimos anos, vêm dispensando o uso de sua pessoa como figura pedagógica central nessas experiências, criando modos mais fluidos e indeterminados de participação e colaboração (BISHOP, 2012, P. 244).

$\mathrm{Na}$ arte contemporânea brasileira há uma quantidade significativa de artistas que trabalham sobre a linha poética da educação, porém de forma independente dos debates europeus e americanos ou de forma muito desinteressada em relação a se apropriar de um termo ou definição ${ }^{12}$. Além de Jorgge Menna Barreto e Ricardo Basbaum, podemos citar como exemplos de artistas que têm obras traçadas com as linhas poéticas dos processos e dispositivos educacionais: Mônica Nador, que desenvolve desde 1996 ações artísticopedagógicas com moradores da periferia de São Paulo, incluindo pintura criativa com estêncil em muros, debates sobre cidadania etc.; Dora Longo Bahia, que desenvolveu, em Anarcademia, projeto para a 28 ${ }^{\text {a }}$ Bienal de São Paulo, em 2008, encontros com um grupo de alunos, com se fosse uma escola de arte, discutindo e produzindo arte contemporânea; Jonathas de Andrade, que se inspirou no método Paulo Freire de alfabetização para criar cartazes educacionais em Educação para Adultos, de 2010; Leandro Cardoso Nerefuh, que faz palestras-performance como em Arquivo Banana, de 2010, com o uso de lousa e projetor sobre conteúdos etnográficos e brasileiros; Cláudio Bueno, que desenvolveu com Tainá Azeredo o projeto Intervalo-Escola, uma plataforma de ações educativas, em colaboração com diversos artistas; inclusive com Jorgge Menna Barreto e Ricardo Basbaum, que participaram na edição que ocorreu em São Paulo e no Amazonas chamada Intervalo-Escola: intervalo em curso.

No Brasil, as discussões sobre as relações entre arte e educação ocorreram, nos últimos anos, com maior frequência sobre a curadoria pedagógica e o setor educativo das instituições de arte, através da palavra-chave "mediação", e com menor intensidade sobre a análise da produção de obras de arte que têm linha poética da educação, como as exemplificadas acima. Mônica Hoff (2014) e Cayo Honorato (2011) estão entre os primeiros pesquisadores a utilizar o termo "virada educacional" no Brasil, para falar dos novos processos educacionais como arte ao interesse crescente sobre modos alternativos e híbridos de mediação da arte em exposições de grande porte, que partem tanto da curadoria quanto dos artistas. Hoff vai ser

\footnotetext{
12 Uma grande exposição chamada Há Escolas Que São Gaiolas e Há Escolas Que São Asas sobre as relações entre arte e educação, com destaque para os pensamentos de Anísio Teixeira, Paulo Freire e Darcy Ribeiro, aconteceu em 2014 no Museu de Arte do Rio (MAR), com curadoria de Paulo Herkenhoff e Janaina Melo. Entre os muitos artistas incluídos, podem ser citados Jorgge Menna Barreto, Ricardo Basbaum, Jonathas de Andrade, Vitor Cesar, Graziela Kunsch, Cinthia Marcelle, Elida Tessler, Marilá Dardot, Almeida Júnior, Anna Bella Geiger, Lenora de Barros.
} 
mais direta em sua dissertação de mestrado $^{13}$, em vista de sua experiência próxima do fenômeno, já que discussões similares às europeias estavam acontecendo desde 2006 em

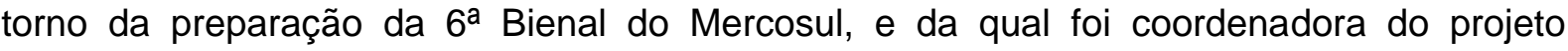
pedagógico.

Entre 2006 e 2008, ou seja, logo depois que Jorgge Menna Barreto propôs Projeto Matéria, o termo "virada educacional" (educational turn) tornou-se comum para definir um fenômeno, crescente entre artistas, curadores e instituições de arte, composto de interesses muito amplos sobre os processos e dispositivos educacionais. A criação do termo e a intensificação do fenômeno no contexto europeu e americano aconteceram na sequência do cancelamento da Manifesta de 2006. A bienal, que acontece cada vez em uma cidade europeia diferente e que naquele ano deveria acontecer em Nicósia ${ }^{14}$, impulsionou essas relações entre educação e arte no mundo todo. Em vez de uma exposição, o artista Anton Vidokle ao lado de outros dois curadores, Florian Waldvogel e Mai Abu EIDahab, imaginaram uma escola de arte temporária, composta de departamentos que pudessem discutir e propor modelos de transformação para a educação e a cultura na realidade daquela cidade. Contra a proliferação de bienais pelo mundo e o caráter monótono dessas exposições, que sempre ocorrem da mesma forma, os curadores pensaram na possibilidade de substituir o modelo de exposição tradicional de bienal por uma escola de arte temporária, uma escola como exposição. Sobre a problematização da participação do público nas exposições de arte, Anton Vidokle (2009, p. 189-200) diz que o público é envolvido em situações em que deve participar de forma mais ativa, e isso tem ocorrido, segundo ele, com menor frequência na arte. A escola, então, seria um modelo que apontaria uma nova relação das pessoas com a arte, de forma mais engajada. A escola de arte é um lugar multidisciplinar por natureza, onde a experimentação é encorajada; lugar do conhecimento, da pesquisa, da discussão, da crítica, da colaboração e da amizade ${ }^{15}$. Não só lugar de aprendizado, mas também de produção

\footnotetext{
${ }^{13}$ Em sua dissertação de mestrado, Mônica Hoff faz um panorama do fenômeno, relacionando a situação nos EUA e Europa com o Brasil, questionando o que levou artistas, nestes últimos anos, a pensar em exposições de arte como se fossem escolas, ainda que temporárias, ao mesmo tempo que curadores passaram a atuar numa perspectiva educacional, dentro e fora das instituições. Além da própria Bienal do Mercosul como uma bienal pedagógica, Hoff faz um recorte de análise com dois outros exemplos brasileiros, os Domingos de Criação, eventos artístico-educativos experimentais ocorridos no MAM do Rio de Janeiro em 1971, organizados por Frederico Morais; e o Café Educativo de Jorgge Menna Barreto. Ver: Hoff, 2014.

${ }^{14}$ A cidade de Nicósia, capital da República do Chipre, está dividida entre gregos e turcos. Os turcos ocupam a parte norte da ilha desde 1974, nomeada como República Turca do Chipre, país não reconhecido pela ONU. Até 2007 a cidade era dividida por muros e barricadas.

${ }^{15}$ Ao final de um ensaio de Anton Vidokle sobre a Manifesta 6 há uma lista de escolas de arte e cursos experimentais, institucionalizados ou independentes, tais como Bauhaus (1919-1933), Vkhutemas (1920-1930), Black Mountain College (1933-1957), as aulas de John Cage na New School for Social Research (1956-1960), o programa Whitney ISP (1968), a Escola de Artes Visuais do Parque Lage (1975), École Temporaire de Dominique Gonzalez-Foerster, Philippe Parreno e Pierre Huyghe (19981999), a Proto Academy criada pelo curador Charles Esche (1998-2002) e a Future Academy, criada por Clementine Deliss (2002), entre outros. Ver: Vidokle, 2006, p. 6.
} 
cultural, com lançamento ou edição de livros e publicações, exposições, performances, teatro; e da organização do conhecimento, o que é visto em seus acervos, arquivos e bibliotecas. Os organizadores locais pediram que o evento ocorresse somente do lado grego da cidade de Nicósia, o que para Vidokle seria inadmissível, por excluir o restante da comunidade. Assim, a três meses de seu início, a Manifesta foi cancelada. Com outros artistas e teóricos que estavam no projeto, Boris Groys, Martha Rosler, Liam Gillick, Walid Raad, Jalal Toufic, Nikolaus Hirsch e Tirdad Zolghadr, a ideia foi levada de forma independente para Berlim, com o nome de unitednationsplaza. A escola ocupou o primeiro andar em cima de um supermercado localizado na Platz der Vereinten Nationen em Berlim. Durante um ano realizou-se uma série de seminários, performances, conferências, palestras e projeção de filmes sobre arte contemporânea e temas políticos. A partir de então, vários museus, escolas de arte e publicações da Europa e dos Estados Unidos lançaram conferências, seminários, livros ou edições especiais de revistas para analisar o interesse tanto dos artistas quanto dos curadores e instituições sobre o tema da Educação.

Uma das primeiras pesquisadoras a utilizar o termo educational turn foi Irit Rogoff, professora do programa de Curadoria e Conhecimento do Goldsmiths College de Londres, no texto Turning, de 2008. Além de propor uma estética pedagógica, Rogoff (2010, p. 32-46) assinala que trazer o tema da Educação por si só para o trabalho artístico ou curatorial não é garantia de uma educação livre e sem hierarquia nem de um trabalho mais ativo e eficiente de relevância crítica, entendimento ou de transformação dos espaços de exibição e interação. Contudo, por não estar sujeito a instituições acadêmicas já formatadas, o fenômeno sugere abertura e invenção de um novo espaço de participação e diálogo. O texto faz parte da coletânea Curating and the Educational Turn, livro que reforçou a ideia de "virada educacional", organizado em 2010 pelo curador irlandês Paul O'Neill e pelo artista irlandês Mick Wilson, hoje professor da Universidade de Gothenburg, na Suécia. O livro demarca a discussão, no âmbito da curadoria, sobre a virada educacional, trazendo textos de pesquisadores e artistas que perceberam, definiram e divulgaram o termo, ligando variadas práticas ao fenômeno. Para os editores O'Neill e Wilson (2010, p. 11-22), a educação é uma preocupação característica da curadoria contemporânea, ao trazer para o museu formatos, métodos, programas modelos e processos pedagógicos e do universo da educação ou da arte-educação. De uma forma ou de outra, o livro vai tentar explanar as práticas artísticas e curatoriais que se tornaram tendência nas principais bienais, exposições, feiras de arte e seminários, ao incluir o aspecto educacional como norteador das linhas curatoriais e também de linhas poéticas das obras de arte, ou ainda daqueles casos em que não existe definição sobre ser um projeto artístico ou curatorial. Nessa tendência há uma profusão de debates, discussões, simpósios, programas educativos, debates e práticas discursivas. 
"Virada educacional" é uma expressão usada para definir um fenômeno recente de movimentação da arte sobre o campo da educação e é também palavra-chave que se associa a diversas preocupações e interesses de artistas, curadores, pesquisadores e instituições de arte, tais como: processos e dispositivos educativos como obra de arte; processos de mediação entre o público e a produção artística; arte-educação; o setor educativo e de mediação em museus e exposições; museografias e curadorias pedagógicas; a educação artística; as escolas e universidades de Artes; a obtenção de títulos por parte do artista, para que ele possa dar aulas (ou ser pesquisador), dependendo do nível de ensino almejado e requerido, da licenciatura à pós-graduação stricto sensu; a criação de espaços independentes de ensino e pesquisa, entre outros tópicos.

\section{Conversas coletivas}

Ricardo Basbaum desenvolveu uma relação entre os circuitos da arte e a universidade, sendo a produção de pensamento uma das questões mais importantes do seu trabalho. As oficinas aparecem em duas séries que o artista desenvolve, eu-você: coreografias, jogos e exercícios e conversas-coletivas. Basbaum (2013a, p. 18-20) diz que tem interesse nessa prática que se dá a partir da oficina, porque existe uma transformação na relação entre artista e público, que começa a acontecer de forma mais direta e horizontal, tendo em vista um trabalho coletivo. "E aí também se misturam vários outros modos de prática, como por exemplo o modo da produção de discurso, a conversa - a oficina é um lugar de leituras, de escrita, de trocas". Os trabalhos de conversas-coletivas começam com convites ou chamada pública para a formação de um grupo de pessoas que participará de uma oficina. Pessoas específicas, convidadas ou selecionadas, começam a fazer parte da obra em torno de um tema proposto para discussão, que pode ser diferente de cidade para cidade ${ }^{16}$, e depende do contexto da exposição e do grupo formado.

\footnotetext{
${ }^{16}$ conversas-coletivas vem acontecendo desde 2010 em variados momentos e cidades, tais como São Paulo (em 2016 na Casa Tomada, dentro do projeto Intervalo Escola de Claudio Bueno e Tainá Azeredo), Hamburgo (Stadtkuratorin, projeto de intervenção urbana), Estocolmo (Tensta Konsthall), Rio de Janeiro (Centro de Arte Hélio Oiticica e Festival Atos de Fala), Bienal de Kiev, Viena (Exposição CounterProduction e Academia de Belas-Artes de Viena), Santiago de Compostela (CGAC), Londres (The Showroom), Curitiba (Exposição Campo Neutral), Bienal de Busan, Guimarães (intervenção urbana no projeto Reakt - Olhares e Processos), Chicago (Logan Gallery da Universidade de Chicago) etc.
} 


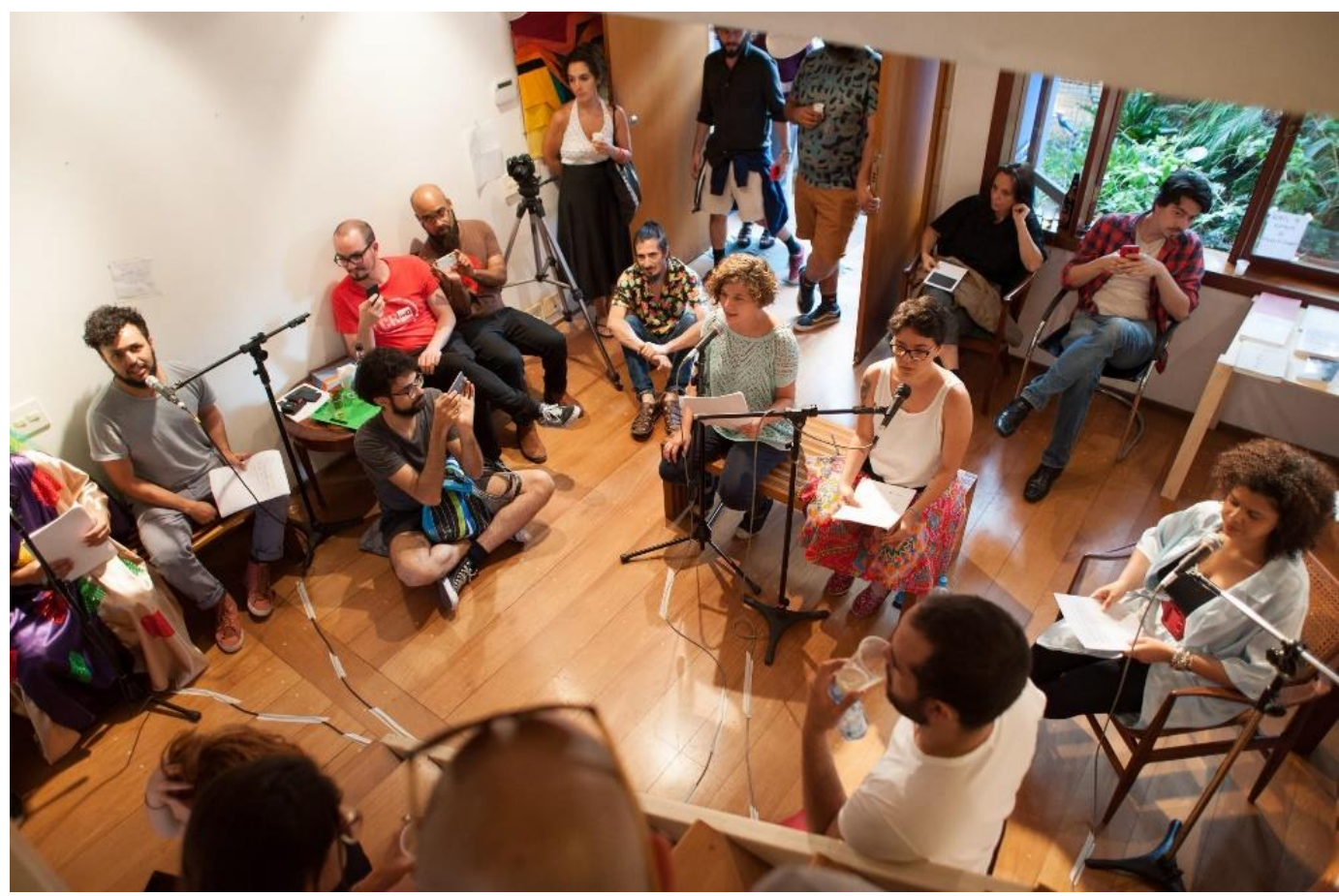

Fig. 4 - Ricardo Basbaum, conversa-coletiva (intervalo-escola), 2016, leitura ao vivo e gravação com Bárbara Lopes, Bruno Alves de Almeida, Cláudio Bueno, Fábio Tremonte, Haroldo Saboia, Júlia Milward, Kadija de Paula, Noara Quintana, Paz Ponce, Pérez-Bustamante, Ricardo Basbaum, Suelen

Pessoa, Tainá Azeredo, Valdinaldo Martins da Silva. Apresentada na Casa Tomada, São Paulo (fotografia: Casa Tomada; cortesia do artista)

O artista diz que trabalha "com um grupo, na dimensão de um workshop ou de uma oficina", trazendo "algumas questões para deflagrar a conversa". Desse modo, depois de um tempo de encontros, há a redação e a formatação de um documento na forma de script, parecido com um roteiro de peça de teatro ou partitura musical, mas "um texto coletivo, de muitos autores". O texto é pensado e elaborado por todos do grupo, dentro das dinâmicas propostas nos encontros da oficina. $O$ intuito da conversa-coletiva é ser uma leitura pública desse script, em certa proximidade com a performance e até com a palestra-performance (no caso, coletiva). Ricardo Basbaum inventa outro tipo de arte, próxima da orquestra de câmara ou da roda de samba, mas no lugar dos instrumentos musicais são utilizados falas, pensamentos e ideias.

Todos leem sentados, geralmente em círculo, cada um com um microfone. Utilizam-se, tal como instruído pelo script, recursos musicais e sonoros como refrões, coros, jograis, falas, diálogos, simultaneidade, barulhos e ruídos, palmas, improvisações. Conversas-coletivas, segundo Ricardo Basbaum, são uma maneira de "reconhecer na questão da escrita, quando lida, um mecanismo de produção de fala; reconhecer num endereçamento público da escrita o lugar da voz em público, que é um canto; e reconhecer os aspectos de sonoridade deste processo, da escrita, da leitura, da conversa"17. Ao final da experiência, resta a gravação da

\footnotetext{
${ }^{17}$ Entrevista para esta pesquisa.
} 
conversa, realizada no dia da leitura pública, muitas vezes disponibilizada ao público em um fone de ouvido no espaço da exposição.

Para o artista, a ação coletiva na forma de dinâmica de grupo, que vai resultar no script, dura enquanto o grupo está reunido, lendo, escrevendo, fazendo parte. "A aula formalizada está na escola e na universidade, mas a aula formalizada vem desse lugar, desse encontro. Antes de ter escola, ou universidade, tinha isso: as pessoas juntas conversando e tentando pensar, em um processo de escuta e fala"18. O resultado textual e sonoro é a produção desse roteiro ou partitura, que fica entre o poético, o teórico e a fala cotidiana, feita a partir de um coletivo de vozes criado como se fosse uma colagem de trechos de vários autores que, no limite, seriam citações, como as de um artigo científico, como uma colagem hipertextual de pensamentos. A imagem da oficina, nesse caso, é a imagem de um grupo de pesquisa a investigar um tema específico ou conjunto de temas, dependendo do interesse individual das pessoas que se propuseram a fazer parte e dentro de um breve período de tempo. Além disso, todos os desdobramentos de conversas-coletivas acontecem como processo de pesquisa do próprio artista sobre a discursividade do som e a musicalidade da fala. Os artistas convidados trazem suas pesquisas artísticas para dentro do projeto, por isso o momento da conversacoletiva é uma reflexão sobre a pesquisa tanto de Ricardo Basbaum quanto dos participantes, e isso fica evidente no script produzido (BASBAUM et al., 2012, p. 30-51).

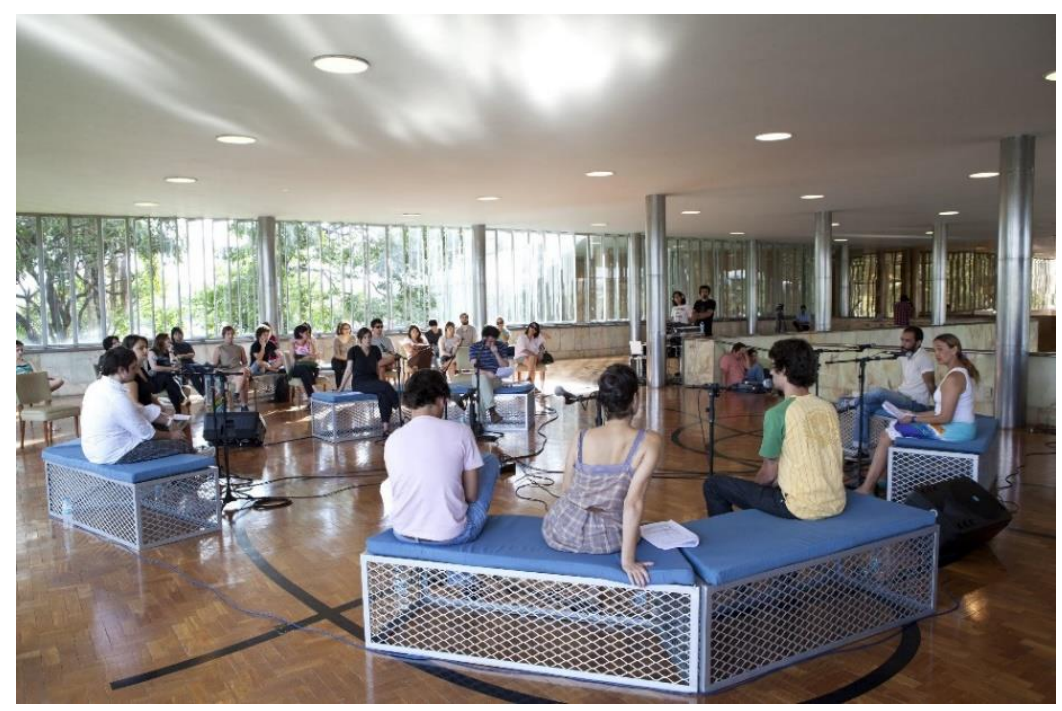

Fig. 5 - Ricardo Basbaum, conversa-coletiva (re-projetando belo horizonte), 2012, leitura ao vivo e gravação com Aruan Mattos, Breno Silva, Brígida Campbell, Daniel Escobar, Flávia Regaldo, Fred Paulino, Renata Marquez, Ricardo Basbaum, Silvana Stein. Apresentada no Museu de Arte da Pampulha, Belo Horizonte (fotografia: Daniel Mansur; cortesia do artista)

Não é somente um laboratório de experimentações com as sonoridades do texto lido, mas pode-se pensar em um laboratório de pesquisas muito mais amplo de investigação

\footnotetext{
${ }^{18}$ Entrevista para esta pesquisa.
} 
(científica e artística) sobre as associações de pessoas, sobre os temas artísticos, sobre outros campos do conhecimento que os participantes estejam estudando. As muitas vozes das conversas-coletivas são como se fossem as vozes de uma pesquisa acadêmica populada por autores e citações como contribuições à pesquisa em curso. O artista agencia interesses de projetos que têm uma urgência e uma atualidade, por exemplo, em torno da cidade, da participação, da colaboração e de várias linhas poéticas que partem do social ou da política, ou de outros temas importantes para a arte contemporânea, em uma produção de pensamento que nasce da conversa, um "pensamento-voz".

\section{Linha poética da pesquisa}

Ricardo Basbaum diz que muitos curadores e críticos identificam no trabalho dele uma relação com o campo da educação, e em muitas exposições ele foi chamado mais pelo educativo do que pela curadoria da exposição. $O$ artista diz reconhecer a importância das relações da arte com a educação, principalmente sobre seu trabalho, mas que não quer que este seja lido apenas por essa linha poética:

Eu não quero que meu trabalho seja colocado no nicho educativo, eu acho que não deve existir esse nicho. Pra mim essas questões da educação ou da pesquisa, eu tento, na medida do possível, trazê-las pra dentro da construção de linguagem, do dispositivo que é o meu trabalho. ${ }^{19}$

Em muitos momentos, o fenômeno do artista-professor é o mesmo do artistapesquisador, por isso tanto a pesquisa artística quanto a teoria de artista são linhas poéticas que estão em evidência nos projetos de Ricardo Basbaum e de Jorgge Menna Barreto. Uma leitura atenta e forte de suas dissertações e teses (textos originados, inclusive, quando estes eram alunos da pós-graduação stricto sensu em Artes), revela o intrincado funcionamento de suas obras de arte. Categorizações muito rígidas que surgem a partir de viradas e movimentos artísticos acabam sendo muito amplas na tentativa de abarcar, ou antes, envelopar poéticas complexas de artistas como eles, ainda que estes tenham em seus projetos poéticos a linha da educação como um traço importante e evidente, com reconhecimento entre artistas, curadores e pesquisadores das artes ${ }^{20}$. No entanto, isso pode fazer com que a obra e o texto do artista sejam vistos por um único ângulo e que outras linhas poéticas acabem passando despercebidas. "As aulas foram uma parte da minha vida, eu as dei com paixão. Não são de modo algum como as conferências, porque implicam uma longa duração, e um público

\footnotetext{
${ }^{19}$ Entrevista para esta pesquisa.

${ }^{20}$ No caso de Jorgge Menna Barreto, essas linhas poéticas da educação são mais evidentes. Podemos citar, entre muitos exemplos a esse respeito, o I Prêmio Select de Arte e Educação, do qual foi ganhador em 2017. O artista, que já atuou como coordenador do setor educativo do Paço das Artes e fez curadoria pedagógica na Trienal de Sorocaba em 2015, tem uma trajetória consistente sobre as relações entre arte e educação. Ver: Barreto, 2014, p. 214-223.
} 
constante, às vezes de vários anos", diz Gilles Deleuze (2010, p. 173) em entrevista de 1988, concedida a Raymond Bellour e François Ewald, respondendo a uma pergunta sobre o que é dar aula. "É como um laboratório de pesquisas: dá-se um curso sobre aquilo que se busca e não sobre o que se sabe".

A tese de doutorado Acts of Research, de Sidsel Nelund (2014), professora e pesquisadora na Real Academia de Belas-Artes da Dinamarca, estuda como a ideia de conhecimento vem sendo trabalhada de modo intenso nas Artes Visuais dos últimos anos, e no momento em que a palavra-chave "produção do conhecimento" começa a fazer parte do discurso artístico, a partir de três nós poéticos: 1) a pesquisa artística; 2) a curadoria de pesquisa e 3) as relações da arte com a educação, ou o que ela chama de pesquisa educacional. A autora tenta entender por que artistas, curadores e teóricos da arte começam a utilizar o conceito de "produção do conhecimento", originalmente utilizado pelo discurso neoliberal, já que o termo tem origem nas ideias sobre o valor econômico e ideológico da educação e da pesquisa da Escola Austríaca, em nomes como Friedrich Hayek e Fritz Machlup, e que estará na base das ideias de produção do conhecimento, tal como foi estabelecida no influente livro de 1994, The New Production of Knowledge: Dynamics of Science and Research in Contemporary Societies, de Camille Limoges, Helga Nowotny, Peter Scott, Martin Trow e do sociólogo brasileiro Simon Schwartzman, e que serviu de inspiração para grandes reformulações do ensino e da pesquisa em vários países (NELUND, 2014, p. 59-70). Nelund fundamenta a ideia de "atos de pesquisa" como uma prática, um processo e uma metodologia de trabalho para a arte, no caminho dos filósofos Paolo Virno, Gilles Deleuze e Félix Guattari. A autora diz que os atos de pesquisa (artística, educacional ou curatorial) estão apoiados em regras, modos de produção preestabelecidos e em regimes hegemônicos de conhecimento, porém a arte deve subverter esses parâmetros e, de forma crítica, apontar para os limites existentes, em direção a contextos históricos e sociopolíticos. Nelund também investiga a ideia de produção do conhecimento sobre a curadoria de pesquisa ou como a pesquisa artística esteve presente em mostras como a Bienal de Havana de 1989 e a Documenta 13, de 2012. A autora apresenta um posicionamento interessante sobre o fenômeno, ao enxergar essas relações da arte com o conhecimento não só pelo viés das questões institucionais da arte ou da universidade, mas também ao discutir a produção artística, quando traz trabalhos de Hito Steyer, Rabih Mroué, Otolith Group, no caso da pesquisa artística, e Cátedra Arte de Conducta, de Tania Bruguera, e Copenhagen Free University, de Henriette Heise e Jakob Jakobsen, como exemplos de projetos educacionais. Utilizar a palavra-chave "produção do conhecimento" foi a maneira que a pesquisadora dinamarquesa encontrou para dar conta do fenômeno da arte sobre o conhecimento, que abrange o relacionamento da arte com a pesquisa e a educação intensificado a partir dos 
anos 2000, e que dá origem a outras palavras-chave como "pesquisa artística", "curadoria de pesquisa", "projetos educacionais" e "práticas discursivas".

Projeto Matéria tem uma imagem potente do ambiente de pesquisa e do ambiente teórico, sendo também um exemplo recente de pesquisa em arte na universidade, criada sob o impacto da entrada de Jorgge Menna Barreto no mestrado em 2004: "nela podemos perceber os influxos reflexivos que irão caracterizar os anos no programa de pós-graduação" (BARRETO, 2007, p. 121-126). Segundo o artista, o "meio acadêmico não somente tem ocupado um lugar de destaque, como influenciado grande parte da minha produção de maneira indelével [...] gerando híbridos como o Projeto Matéria" (BARRETO, 2012, p. 10). Jorgge Menna Barreto começou a se dar conta de como os artistas acabam sendo repetidores de metodologias de trabalho que são ensinadas na graduação e que, muitas vezes, os cursos não fornecem as ferramentas de questionamento do próprio método. Desse modo, o mestrado, para o artista, é "uma volta para a academia", uma promessa de "recuo crítico", um momento reflexivo sobre a obra de arte que se contrapõe ao modo acelerado das bienais e exposições: "Em qual outro momento do sistema da arte que a gente tem o privilégio de se dedicar a uma questão por tanto tempo? E descompactar isso. E pensar, e estender, e estirar e [...]. Então, eu acho um privilégio poder ter feito um mestrado, um doutorado, um pós-doc"21. O artista diz que não teria conseguido construir seu projeto poético sem essa experiência de pesquisa artística, que se desdobrou em um espectro muito amplo de atividades, que inclui dar aulas, orientar projetos, participar em congressos e seminários, e que também se expandem para circuitos fora da universidade como, entre outras práticas, coordenar em 2007 o educativo do Paço das Artes, em São Paulo, fazer parte do corpo de críticos do CCSP, entre 2008 e 2010, ou coorganizar com Helmet Batista o programa de palestras e oficinas chamado "Máquina de Responder", dentro das atividades que o Capacete propôs para a 29a Bienal de São Paulo, em 201022. Desse modo o artista circula por um campo muito aberto de debates e questionamentos, dentro ou fora da universidade, como professor ou pesquisador, abrindose para o mundo exterior, para outros campos do conhecimento e para o embate com o público:

\begin{abstract}
Eu acho que tem algo que me dei conta no mestrado, é como a sala de aula se torna o teu ateliê e teu processo se torna público. Então, você passa a incluir todos esses outros discursos de autores, de orientador que lê o seu texto e dos colegas que estão participando junto com você em uma disciplina de metodologia; de repente tu tens uma complexidade de vozes que te traz um estado de presentidade,
\end{abstract}

\footnotetext{
${ }^{21}$ Entrevista para esta pesquisa.

${ }^{22}$ Capacete é um programa de residências artísticas de pesquisa fundada em 1998 por Helmut Batista, com sede no Rio de Janeiro, promovendo também oficinas e palestras.
} 
porque daí você está no mundo mesmo, você está ali trazendo as suas questões íntimas para uma esfera que é pública, de discussão pública ${ }^{23}$.

A universidade é mais um lugar de atuação para o artista, lugar que permite uma associação produtiva com outros campos do saber, dando origem a pesquisas, teoria e aulas. Além de ser uma ferramenta de reflexão artística, ajuda o artista a articular conceitos envolvidos em sua obra e na obra de outros artistas, dando origem a uma atividade plural que oscila entre o poético e político. Segundo Jorgge Menna Barreto, "a sala de aula também pode tornar-se um ambiente de ativismo cultural e político exercido pelo artista"24.

As aulas de Projeto Matéria partiram da ideia de site-specific como tema e processo de pesquisa, um estudo para o desenvolvimento de métodos e estratégias artísticas. São problemas que resultaram em outras obras e em sua dissertação de mestrado chamada Lugares moles, defendida em 2007. A ideia de site-specific está associada geralmente a certas experiências artísticas realizadas entre os anos 1960 e 1970 (KRAUSS, 2008), aplicando-se a obras de arte que ocupam ou transbordam para lugares não institucionais da arte, um ponto na natureza ou do espaço urbano, um lugar qualquer ou com uma especificidade histórica, acrescidos ou não de contexto ou ação do artista. O próprio lugar, a partir de intervenções efêmeras ou permanentes, pode tornar-se uma obra de arte. Jorgge Menna Barreto é estudioso e tradutor das ideias da crítica coreano-americana Miwon Kwon, professora de História da Arte na Universidade da Califórnia. Kwon (2002) faz a passagem da ideia de site-specific dos minimalistas para uma ideia de site-specificity mais ampla, em que a pesquisa histórica, social ou institucional sobre o lugar tem mais importância do que as relações espaciais, materiais ou formais. A autora diferencia o modo fenomenológico do sitespecific feito nos anos 1970, exemplificado com as esculturas de Richard Serra, de trabalhos feitos a partir da década de 1980, geralmente relacionados à crítica institucional, à arte social e participativa, em uma relação mais próxima com a política, a comunidade e os movimentos sociais, em nomes como Andrea Fraser, Group Material, Christian Philipp Müller, Renee Green, Mark Dion, entre outros, em que a preponderância poética se dá sobre a discursividade do lugar, sobre um campo de operação discursiva.

A partir daí, o lugar específico expande-se para uma condição de espaço discursivo, o site se torna discursivo, até o ponto em que uma tese de doutorado ou uma dissertação de mestrado pode ser também um lugar específico e uma obra de arte, que tem o leitor como elemento do jogo proposto por essa construção relacional e colaborativa. Jorgge Menna Barreto (2007, p. 11) diz que "as práticas site-specific, ou as práticas artísticas específicas para um contexto, desconstroem a ideia do lugar como um suporte neutro para a obra e o

\footnotetext{
${ }^{23}$ Entrevista concedida por Jorgge Menna Barreto para esta pesquisa.

24 Juliana Monachesi e Tatiana Ferraz. Arte e universidade - novas estratégias de reflexão, 2003.
} 
ativam como parte integrante do trabalho"25. O artista quer tornar também seu texto teórico, através de uma operação artística do tipo site-specific, em uma obra de arte participativa, em um jogo metalinguístico em que teoria e arte se confundem.

Em 2004, mesmo ano em que Projeto Matéria foi exibido, Ricardo Basbaum (2013b) publicou o texto "Amo os artista-etc.", originalmente em inglês como "I love etc.-artists", em resposta ao projeto The Next Documenta Should Be Curated By An Artist, de Jens Hoffman (2004). A participação de Ricardo Basbaum aconteceu em um momento de compreensão do processo de "autoprodução do artista", diz ele, que "estava mergulhado nesse problema, de como a gente se pensa como artista" ${ }^{26}$. Em Ricardo Basbaum, os conceitos e a teoria são inseparáveis da produção artística, e esse é um dos seus posicionamentos mais fortes, que pode ser compreendido através da ideia de artista-etc., uma nova imagem para o artista, que agora se desdobra em vários circuitos da arte, como curador, pesquisador, editor, crítico, teórico, agenciador, professor etc. Partindo desse artista-etc., no recorte que Jorgge Menna Barreto faz do artista como pesquisador, e em uma aproximação da arte com a leitura de textos poéticos ou textos teóricos, o artista é um artista-leitor, que no meio acadêmico ou fora dele faz a leitura do mundo, de livros e de artistas. Dentro ou fora da universidade, o artista traz o processo da pesquisa para seus projetos poéticos, primeiramente como um método que ajuda na prática artística, até o momento que a obra se torna peça de um sistema conceitual complexo, composto de outras peças espalhadas e conectáveis.

\section{Considerações finais}

Jorgge Menna Barreto e Ricardo Basbaum são professores universitários, autores de textos importantes para a arte brasileira na forma de artigos, dissertações e teses, criam conceitos artísticos para lidar com suas próprias obras ou a de outros artistas, com intensa atividade de publicações em revistas e livros, criam aulas, oficinas, palestras e outras produções discursivas consideradas obra de arte; transitam de forma ativa em grandes exposições e bienais, bem como em variadas esferas e instituições; trazem a arte para perto do conhecimento e o pensamento, considerados em sua face coletiva e pública, em uma discussão teórica que pede a colaboração de outros artistas e profissionais da Arte, e também pesquisadores de outras áreas do conhecimento.

A obra de pesquisa também pode ser considerada uma obra de resistência ao mercado, à institucionalização e à preponderância dos pensamentos instituídos e dominantes, aproximando-se dos debates e das pesquisas políticas e sociais, em variados tópicos trabalhados de forma intensa nos últimos anos. Jorgge Menna Barreto e Ricardo Basbaum

\footnotetext{
${ }^{25}$ Jorge Menna Barreto, Lugares moles,

${ }^{26}$ Entrevista para esta pesquisa.
} 
representam uma geração de artistas que encontrou na universidade pública brasileira um lugar para a produção, a reflexão e a conversa, em torno de questões como a discursividade, a participação, o convívio, o lugar, o público. O uso de meios desmaterializados como palestras, aulas, discussões e encontros propiciou uma mudança de status e do lugar do fazer artístico, expandindo a noção do lugar para incluir contextos sociais e políticos. Os artistas, por uma questão de necessidade de outros espaços e engajamentos, começam a trabalhar de forma expandida, fora do estúdio e das instituições. Ocupam outros lugares que não são aqueles até então recorrentes ou convencionais à exibição de arte, ou sentem uma necessidade de subvertê-los, transformando-os de suas funções originais. Desse modo, a obra de arte expande-se e intensifica-se como um campo de conhecimento, troca intelectual, debate e cultura.

\section{Referências}

BARRETO, Jorgge Menna. Anotações sobre uma certa inclinação educativa de em uma trajetória (supostamente) artística. Urbânia, n. 5, São Paulo, 2014, p. 214-223.

BARRETO, Jorgge Menna. Exercícios de leitoria. Tese (Doutorado em Poéticas Visuais) - Escola de Comunicações e Artes, Universidade de São Paulo, 2012.

BARRETO, Jorgge Menna. Lugares moles. Dissertação (Mestrado em Poéticas Visuais) - Escola de Comunicações e Artes, Universidade de São Paulo, 2007.

BASBAUM, Ricardo. Carbono entrevista Ricardo Basbaum. Entrevista concedida a Marina Fraga. Revista Carbono, n. 2, Rio de Janeiro, 2013a. Disponível em: https://bit.ly/2YIBJDQ. Acesso em: 23 out. 2016.

BASBAUM, Ricardo. Amo os artistas etc. In: . Manual do artista-etc. Rio de Janeiro: Beco do Azougue, 2013b, p. 167-170.

BASBAUM, Ricardo et al. Roteiro conversa coletiva: re-projetando (belo horizonte). In: BASBAUM, Ricardo; MARQUEZ, Renata (org.). conjs., re-bancos*: exercícios\&conversas. Catálogo de exposição. Belo Horizonte: Museu de Arte da Pampulha, 2012, p. 30-51.

BEUYS, Joseph. I Am Searching for Field Character. In: KUONI, Carin (org.). Energy Plan for the Western Man: Writings by and Interviews with the Artist: Joseph Beuys in America. New York: Four Walls Eight Windows, 1990, p. 21-23.

BEUYS, Joseph. A revolução somos nós. In: FERREIRA, Glória; COTRIM, Cecília (org.). Escritos de Artistas. Anos 60/ 70. Rio de Janeiro: Zahar, 2009, p. 300-324.

BEUYS, Joseph; BÖLL, Heinrich. Manifesto on the Foundation of a "Free International School for Creativity and Interdisciplinary Research". In: TISDALL, Caroline. Art into Society, Society into Art: Seven German Artists. London: Institute of Contemporary Art, 1974, p. 49-50.

BISHOP, Claire. Antagonism and Relational Aesthetics. October, n. 110, p. 51-79, Fall 2004.

DELEUZE, Gilles. Conversações. São Paulo: Editora 34, 2010.

FILLIOU, Robert. Teaching and Learning as Performing Arts. New York: Kasper König, 1970.

HOFF, Mônica. A virada educacional nas práticas artísticas e curatoriais contemporâneas e o contexto de arte brasileiro. Dissertação (Mestrado em Artes Visuais) - Instituto de Artes, Universidade Federal do Rio Grande do Sul, Porto Alegre, 2014.

HOFFMAN, Jens (ed). The Next Documenta Should Be Curated By An Artist. e-flux Projects. 2004. Disponível em: https://bit.ly/34GXdEU. Acesso em: 23 jan. 2016. 
HONORATO, Cayo. A formação do artista: conjunções e disjunções entre arte e educação. Tese (Doutorado em Educação) - Faculdade de Educação, Universidade de São Paulo, São Paulo, 2011.

KAPROW, Allan. Essays on the Blurring of Art and Life. Organização de Jeff Kelley. Los Angeles: University of California Press, 1993.

KRAUSS, Rosalind. A escultura no campo ampliado. Arte \& Ensaios, n. 17, p. 128-137, EBA/ UFRJ, Rio de Janeiro, 2008. Disponível em: https://bit.ly/34JC794. Acesso em: 26 jan. 2016.

KWON, Miwon. One Place After Another: Site-specific Art and Locational Identity. Cambridge: MIT Press, 2002.

NELUND, Sidsel. Acts of Research: Knowledge Production in Contemporary Art between Knowledge Economy and Critical Practice. Tese (Doutorado em Artes e Estudos Culturais) - Institut for Kunst og Kulturvidenskab, University of Copenhagen, Copenhagen, 2014.

O'NEILL, Paul; WILSON, Mick (ed.). Curating and the Educational Turn. London: Open Editions, 2010.

ROGOFF, Irit. Turning. In: O'NEILL, Paul; WILSON, Mick (ed.). Curating and the Educational Turn. London: Open Editions, 2010, p. 32-46.

VIDOKLE, Anton. From Exhibition to School. Notes from unitednationsplaza. In: MADOFF, Steven Henry (ed.). Art School: Propositions for the 21st Century. Cambridge, Massachusetts: MIT Press, 2009, p. 189-200.

VIDOKLE, Anton. Exhibition as School in a Divided City. In: VIDOKLE, Anton; WALDVOGEL, Florian; EL-DAHAB, Mai Abu (ed.). Notes for an Art School: Manifesta 6. 2006. Disponível em: https://bit.ly/32CCBuG. Acesso em: 4 jan. 2016.

ZACCAGNINI, Carla. Dissertação: a obra como lugar do texto, o texto em lugar da obra. Dissertação (Mestrado em Poéticas Visuais) - Escola de Comunicações e Artes, Universidade de São Paulo, São Paulo, 2004. 